\title{
The Compression Behaviour of Concrete Filled Steel Tube columns: Experimental and Numerical Investigation
}

\author{
A.S. Shakir, Z.W. Guan, S.W. Jones
}

\begin{abstract}
The use of Concrete Filled Steel Tube columns becomes increasingly popular in the structural engineering field due to the advantages such as high bearing capacity, ductility and economic efficiency. Many experimental and numerical studies have been undertaken to investigate the behaviour of normal aggregate concrete filled steel tube NACFST columns under quasi static loads. However, few research has been conducted to study the behaviour of the recycled aggregate concrete filled steel tube RACFST columns under compression loading particularly the eccentric loading.

This paper reports the findings of the experimental and numerical study investigating the behaviour of the NACFST and RACFST columns subjected to axial concentric and eccentric loading. Eighteen structural circular hollow tubes with a length of $458 \mathrm{~mm}$ and an outer diameter (D) of $114.3 \mathrm{~mm}$ were tested; half of them were filled with recycled aggregate concrete while the others were filled with normal aggregate concrete. The study has been carried out to examine the influence of several parameters such as the tube thickness i.e. 3 and $3.6 \mathrm{~mm}$, the concrete type and the load eccentricity. The average 28-day compressive strength of the normal and recycled aggregate concrete cubes was $55 \mathrm{MPa}$ and $52 \mathrm{MPa}$, respectively. The finite element models were developed using commercial code ABAQUS/Explicit, which were validated against the experimental results. There are two main constituent materials considered to model the compression behaviour of RACFST and NACFST columns i.e. the concrete core and the steel tube. In addition, the type and the contact properties between the steel tube and the concrete core are very important to simulate this type of structural members. Three dimensional eight nodes solid element with reduced integration C3D8R was used to simulate the concrete core and the steel tube. The stress-strain curve of the steel tube is assumed to be elastic perfectly plastic, the elastic modulus and Poisson's ratio were $200 \mathrm{GPa}$ and 0.3, respectively. The Concrete Damage Plasticity available model in ABAQUS 6.13 is used in this study to describe the behaviour of the confined concrete core with both tension stiffening and compression hardening definition. The results indicate that both the RACFST and NACFST specimens have a similar deformation shape, and the compression capacity of the RACFST specimens is slightly lower than that of the NACFST. The numerical simulations were in a very good agreement with the experimental results in terms of load-displacement traces and deformation modes for both RACFST and NACFST specimens. It is recommended to use the Recycled Aggregate (RA) concrete in the CFST structural members with consideration of the effect of the RA on the maximum compression capacity.
\end{abstract}

Keywords: compression behavior; concrete-filled steel columns; recycled aggregate; finite element simulation

A.S. Shakir

School of Engineering / University of Liverpool

Liverpool L69 3GQ UK

College of Engineering /, Al Muthanna University

Al Muthanna Province, Iraq

Z.W. Guan

School of Engineering / University of Liverpool

Liverpool L69 3GQ UK

School of Architecture and Environment / Sichuan University

Chengdu 610065, PR China

S.W. Jones

School of Engineering / University of Liverpool

Liverpool L69 3GQ UK 